\title{
Experiência com Atividades Desplugadas do Code.org na Disciplina de Língua Estrangeira de uma Escola Estadual
}

\author{
Sabrina B. Sassi ${ }^{1}$, Cristiano Maciel ${ }^{1,2}$, Vinícius Carvalho Pereira $^{3}$ \\ ${ }^{1}$ Programa de Pós-graduação em Educação - Universidade Federal de Mato Grosso \\ (UFMT) - Cuiabá - MT - Brasil \\ ${ }^{2}$ Instituto de Computação - Universidade Federal de Mato Grosso (UFMT) - Cuiabá - MT \\ - Brasil \\ 3Instituto de Linguagens - Universidade Federal de Mato Grosso (UFMT) - Cuiabá - MT \\ - Brasil \\ sabrinabsassiegmail.com, cmaciel@ufmt.br, viniciuscarpe@gmail.com
}

\begin{abstract}
This paper presents an experience report of teaching the concept of algorithm to students of a full-time elementary and high school in the state of Mato Grosso in English classes, with a view to describe the teacher's view on the use of unplugged computer activities in her classes. Two activities (Happy Maps and Move It, Move It) available on Code.org were carried out, adopting Unplugged Computer Science as a methodology. The results show a great engagement of students and the acceptance of unplugged activities by the teacher and the students.
\end{abstract}

Resumo: Este artigo apresenta um relato de experiência de ensino de conceitos sobre resolução de problemas e algoritmos para alunos de uma escola estadual de ensino fundamental e médio de Mato Grosso, realizada em aulas da disciplina de Língua Inglesa, com objetivo descrever a percepção da professora de Língua Estrangeira - Inglês quanto ao uso de atividades desplugadas em suas aulas. Foram realizadas duas atividades (Happy Maps e Move It, Move It), disponibilizadas pelo Code.org, tendo como metodologia a Computação Desplugada. Os resultados indicam grande participação dos alunos e a aceitação das atividades desplugadas tanto pela professora quanto pelos alunos.

\section{Introdução}

A inserção de conceitos da Computação, enquanto ciência, na Educação Básica tem sido amplamente discutida no cenário mundial e entendida pela Computer Science Teacher Association (CSTA), pela Sociedade Brasileira de Computação (SBC, 2018) e pela Base Nacional Comum Curricular (BNCC) [BRASIL, 2020] como fundamental para a vida na sociedade contemporânea. Inúmeras iniciativas têm sido desenvolvidas para promover o Pensamento Computacional e de Programação na educação brasileira do Ensino Fundamental ao Ensino Médio em diferentes abordagens, com destaque para Jogos, Robótica e Computação Desplugada, tendo se multiplicado nos últimos 10 anos [Santos, Araújo e Bittencourt, 2018] e despertado o interesse de muitos pesquisadores da área da Educação e da Ciência da Computação, como exemplo de pesquisa de Castilho, Grebogy e Santos (2019), que descreve estudo realizado em escola brasileira na educação básica, com ou sem o uso de tecnologia ou trabalhando de forma conjunta e com adaptações dos materiais disponíveis na rede. 
Para Wing (2008), o ensino de conceitos computacionais pode desenvolver nos alunos habilidades do pensamento computacional, tais como resolução de problemas e raciocínio lógico, as quais não se limitam a profissionais da área da Ciência da Computação, mas também contribuem para o ensino de outras ciências, como Química, Física, Matemática, Linguagens, dentre outras, capacitando os alunos a sistematizar e organizar a solução de problemas. A Computação Desplugada compreende atividades que, sem fazer uso de computador [Bell; Witten; Fellows, 2009] envolvem a resolução de problemas para alcançar um objetivo e também auxilia na compreensão de conceitos fundamentais da Ciência da Computação.

Com base nas referências trazida pela BNCC, este estudo tem como objetivo analisar a percepção da professora de Língua Estrangeira - Inglês quanto ao uso de atividades desplugadas para o ensino de conceitos fundamentais da Ciência da Computação. Questionamos quanto ao uso de Computação desplugada ser uma significante alternativa para o ensino de conceitos computacionais na Educação Básica mesmo em cenários de limitado acesso a recursos digitais e em disciplina de Língua Estrangeira Inglês. Na análise, adotamos uma abordagem qualitativa.

\section{A experiência com atividades desplugadas do Code.org}

O trabalho adotou a prática de computação desplugada, relacionando-a à inserção das tecnologias no ambiente escolar e no trabalho pedagógico, com vistas a trabalhar conceitos computacionais sem a presença da tecnologia e utilizou-se do Code.org como referência das atividades desenvolvidas com os alunos. $\mathrm{O}$ planejamento da situação didática ocorreu durante uma semana, realizado pela professora de Língua Estrangeira em parceria com uma aluna de Doutorado em Educação pela UFMT/Cuiabá do Grupo de Estudo LêTece ${ }^{1}$. A proposta de uso de Computação Desplugada foi realizada com 34 alunos do sétimo ano do Ensino Fundamental e 21 alunos do primeiro ano do Ensino Médio em uma Escola Estadual de Mato Grosso, a qual não possui disciplina de Informática nem laboratório com acesso à Internet. O objetivo foi apresentar aos alunos atividades desplugadas para o ensino da computação, desenvolvido em três horas aulas de Língua Estrangeira - Inglês. A ideia surgiu a partir do texto "Studying with Technology estudando com tecnologia”, presente no livro didático da disciplina de Língua Estrangeira [Franco, 2016], abordando o uso da tecnologia na educação. A discussão realizada elencou os seguintes pontos: interesse dos alunos pela área da computação; não disponibilidade de recursos tecnológicos na escola e; possibilidade de estudar conceitos computacionais sem utilizar tecnologia.

O Code.org dedica a "expandir o acesso à Ciência da Computação em escolas e aumentar a participação das mulheres e das minorias não representadas"[Code.org, 2020, p.1]. A expectativa desta organização é que todos os alunos em todas as escolas tenham a oportunidade de aprender Ciência da Computação, assim como aprendem Matemática, Língua Materna, Biologia, Química etc. Sendo uma referência mundial no ensino de programação, dispõe de um catálogo de recursos curriculares, tais como mini games, atividades online e offline e tutoriais para crianças a partir de 4 anos. O Code.org dispõe de um catálogo de cursos, denominados Curso 1 (de 4 a 6 anos), Curso 2 (a partir dos 6 anos),

\footnotetext{
1 Laboratório de Estudos sobre Tecnologias da Informação e Comunicação na Educação (https://sites.ufmt.br/letece/.
} 
Curso 3 (de 8 a 18 anos) e Curso 4 (de 10 a 18 anos), sendo os Curso 3 e Curso 4 continuações do Curso 2 [Code.org, 2020]. Estes cursos usam de um desenho curricular em formato espiral, no qual, os conceitos e habilidades trabalhados são revisados em cada curso à medida que vai se aprofundando. As atividades online possuem tutoriais autoguiados e de ritmo individual, enquanto que as atividades offline são oportunidades cinestésica intencionalmente alocadas que ajudam os estudantes digerir conceitos complicados de modo a relacionar as suas próprias vidas

Neste trabalho, foram desenvolvidas duas atividades desplugadas, lição 1 e 2, disponíveis no currículo Fundamentos de Ciência da Computação desplugados - CS Fundamentals Unplugged no Curso 1 do Code.org. A lição 1- Happy Maps teve como objetivo ensinar os alunos a colaborar com outros colegas, desenvolver habilidades de resolução de problemas, persistir na execução de tarefas difíceis e, no final do curso, criar seu próprio jogo ou história personalizada, que pode ser compartilhada com terceiros [Code.org, 2020]. Esta lição foi trabalhada com dois modelos de atividades; no primeiro modelo, os alunos escreveram instruções precisas enquanto trabalhavam para traduzir as instruções nos símbolos fornecidos; no segundo modelo, os alunos deveriam entender a diferença entre planejar uma sequência e programar esta sequência em uma linguagem apropriada, o que os ajudaria a ganharem experiência escrevendo e lendo por meio de códigos. A lição 2 - Move It, Move It teve como objetivo o reconhecimento de situações em que os alunos possam criar programas para concluir tarefas, prever os movimentos necessários para o colega de equipe do início ao fim, converter movimentos em instruções simbólicas e relacionar algoritmos com programas. Nesta lição, os alunos descreveram por meio dos pontos cardeais (north, south, east e west), em inglês, instruções para obter um resultado.

O trabalho buscou captar e analisar de forma descritiva a situação didática em estudo a partir da perspectiva da professora por meio de uma entrevista realizada após a situação didática, considerando pontos de vista relevantes, tais como a leitura e a importância que se dá ao processo de ensino-aprendizagem e não apenas aos resultados. A professora participante do estudo assinou o Termo de Consentimento Livre e Esclarecido.

\section{Resultados e discussões}

Esta seção apresenta o processo de vivência e as percepções da professora de Língua Estrangeira - Inglês quanto ao uso das atividades desplugadas e à recepção, participação e dificuldades apresentadas pelos alunos participantes durante a situação didática. Durante a entrevista, a professora foi questionada quanto à sua experiência com atividades desplugadas e seu conhecimento sobre o Code.org. Segundo a professora, esta foi a "primeira experiência com atividades desplugadas. Não conhecia o Code.org. Gostei bastante, vou aprimorar e atualizar em minhas práticas pedagógicas". Observa-se que, mesmo diante de algo que desconhecia, a professora não se opôs em conhecer, estudar e aplicar a proposta para seus alunos e, a partir da experiência, analisar a possibilidade de trazer para seu planejamento.

A situação didática se centrou em duas atividades: Happy Maps e Move It. Perguntamos se a professora teve dificuldades com as lições desenvolvidas e se, após essa experiência, poderia incluí-las em seu planejamento. A professora faz a seguinte afirmação: "Não tive dificuldade, até então porque as atividades são bem fáceis, simples e objetivas. 
Utilizaria sim as atividades desplugadas nas minhas práticas pedagógicas. Até então, porque vivemos em uma era tecnológica onde os alunos tem muito acesso à tecnologia".

Além da inclusão em seu planejamento, perguntamos se recomendaria as atividades desplugadas para os colegas de profissão. A professora afirma que recomendaria, justificando que "são atividades fáceis, são atividades bacanas de se trabalhar em sala, são atrativas, atividades que os alunos interagem, independente do conteúdo, eles prestam atenção, eles participam, porque é algo que faz parte do momento deles, da vida deles". Em suas afirmações, a professora evidencia que as atividades desplugadas são de fácil entendimento, chamam a atenção dos alunos e possibilitam a interação entre eles.

Ao propor um novo modelo de atividade, muitas vezes o professor pode se deparar com resistências. Como essa experiência foi a primeira, tanto para a professora quanto para os alunos, questionamos como ela percebe a recepção dos discentes quanto à proposta e a participação deles durante a situação didática. Segundo a professora, os alunos "receberam super bem as atividades e gostaram bastante"; quanto à participação, "mesmo aqueles que tiveram dificuldades, que foi o Ensino Fundamental, eles participaram; todos queriam fazer; pediam auxilio para o professor; pediram mais atividades deste modelo nas aulas, tendo o líder de cada turma, anotado o pedido para levar como uma sugestão para outros professores". É notório que, mesmo que as atividades sejam desenvolvidas com materiais de baixo custo e sem o uso de tecnologia, as atividades desplugadas chamam atenção dos alunos pela proposta que trazem.

Durante a realização de uma atividade, os alunos podem apresentar dificuldades para sua resolução. Ao questionar a professora se, durante as atividades, foi possível observar dificuldades no desenvolvimento das tarefas, ela faz a seguinte afirmação: "Os alunos do Ensino Médio não tiveram dificuldade, mas do Ensino Fundamental, houve sim. Não pela atividade em si, porque a atividade não era difícil, mas os alunos não tinham conhecimento prévio do que era norte, sul, leste e oeste, esquerda, direita, em cima e embaixo, dificuldade em interpretação, sendo necessário constantemente a intervenção e o auxilio do professor". O relato da professora evidencia que as atividades desplugadas foram de fácil entendimento enquanto proposta.

Diante das dificuldades relatadas, perguntamos sobre sua percepção quanto à capacidade de resolução de problemas. Para a professora, "há necessidade de ser trabalhado raciocínio lógico com eles, de maneira lúdica, como as atividades que foram trabalhadas com eles". As atividades desenvolvidas com os alunos do Ensino Fundamental e Ensino Médio são propostas para crianças a partir de 4 anos, ou seja, possíveis de serem trabalhadas desde a Educação Infantil. Na observação realizada pela professora, pode-se perceber que, durante a aplicação da proposta, as dificuldades apresentadas pelos alunos do Ensino Fundamental implicaram na resolução das atividades, exigindo uma presença maior da professora.

\section{Considerações Finais}

Este trabalho apresentou um relato de experiência tendo como foco a percepção de uma professora de Língua Estrangeira - Inglês quanto ao uso de atividades desplugadas em uma turma de Ensino Fundamental e uma turma do Ensino Médio. O estudo desenvolvido apresentou resultados satisfatórios, atingindo o objetivo de apresentar conceitos sobre resolução de problemas e algoritmos por meio de atividades desplugadas. $\mathrm{Na}$ vivência, segundo a professora, os alunos conseguiram realizar as atividades propostas, apresentando 
dificuldades em sua execução apenas os alunos do Ensino Fundamental. Além disso, durante a experiência, os alunos mostraram grande participação, interação e cooperação entre si. Esta experiência nos leva a refletir sobre a possibilidade de inserção de atividades nestes moldes nos livros didáticos utilizados pelas instituições de ensino.

Nesta experiência, foi possível perceber a possibilidade do trabalho interdisciplinar com foco nas habilidades e conceitos computacionais por meio de atividades que envolviam a compreensão e a expressão em língua estrangeira. Durante as atividades, foi possível trabalhar com os alunos a importância quanto à instrução ser compreendida e seguida, tanto em termos do conceito de algoritmo quanto de uso da língua inglesa, a fim de atingir o objetivo proposto. Além disso, foi possível trabalhar vocabulário, pronúncia e conceitos de orientação e localização.

Como trabalhos futuros, esperamos aumentar o tempo de experiência, visto que nossa pesquisa foi limitada pois as aulas foram suspensas devido a pandemia, o que justifica o não envolvimento dos alunos, uma vez que era necessário o assentimento dos pais; realizar uma análise qualitativa das atividades propostas tendo como foco as habilidades envolvidas e a interdisciplinaridade; analisar os relatos dos alunos participantes da proposta. Também, planeja-se realizar experiências buscando contemplar outros conceitos computacionais e relacioná-los com a disciplina de Matemática.

\section{Agradecimentos}

Essa pesquisa contou com o apoio do Conselho Nacional de Desenvolvimento Científico e Tecnológico - CNPq e da Secretaria de Estado de Educação de Mato Grosso-SEDUC.

\section{Referências}

Bell, T.; Witten, I. H.; e Fellows, M. "Computer Science Unplugged”. (2011). Disponível em: $<$ https://classic.csunplugged.org/wpcontent/uploads/2014/12/CSUnpluggedTeachers -portuguese-brazil-feb-2011.pdf $>$. Acesso em: 04/11/2019.

BRASIL, MEC. Base Nacional Comum Curricular-BNCC. Disponível em:< http://basenacionalcomum.mec.gov.br/>. Acesso em: 28/05/2020.

Castilho, M. A.; Grebogy, E. C.; e Santos, I. (2019). “O Pensamento Computacional no Ensino Fundamental I”. In: Workshop de Informática na Escola. pg. 461-470.

Code.org. (2020). Curse 1. Disponível em: $<$ https://studio.code.org/s/course1>. Aceso em:15/02/2020.

Franco, C. de P. "Way to go!”.(2016). Língua Estrangeira moderna - Inglês Ensino Médio. 2.ed. 3v. São Paulo: Ática.

Santos, P. S. C., Araujo, L. G. J.; e Bittencourt, R. A. (2018). “A Mapping Study of Computational Thinking and Programming in Brazilian K-12 Education". FIE - IEEE Frontiers in Education Conference.

SBC. (2018). "Nota Técnica da Sociedade Brasileira de Computação sobre a BNCC-EF e a BNCC-EM, Sociedade Brasileira de Computação". Disponível em: https:/www.sbc.org.br/institucional-3/cartas-abertas/summary/93-cartas-abertas/1197nota-tecnica-sobre-a-bncc-ensino-medio-e-fundamental, Acesso: 17 de Abril de 2020.

Wing, J. M. (2008). “Computational thinking and thinking about computing”. Phil. Trans. R. Soc. A, 366(1881):3717-3725. 